\title{
EDITORIAL
}

\section{Mental Health Challenges and COVID-19 Pandemic}

\author{
Subhash C Parija ${ }^{1}$, Sukanto Sarkar ${ }^{2}$
}

\begin{abstract}
Mental health issues have already emerged as a silent epidemic during the COVID-19 pandemic. From frontline workers to the general population, all have been affected by the wrath of this deadly disease. In these testing times, maintaining an adequate mental health is of prime importance. The healthy way to deal with stress, adapt to new normal lifestyle, and cope positively with the situation is the need for the hour.

Keywords: COVID-19, Mental health, Positive coping, Stress.

SBV Journal of Basic, Clinical and Applied Health Science (2020): 10.5005/jp-journals-10082-02276
\end{abstract}

Mental health issues are one of the major challenges of the COVID-19 pandemic. The noxious mixture of social distancing, isolation, quarantine, lockdown, uncertainty, suffering, witnessing painful death, illness-related stigma, and overburdened healthcare system is affecting the mental health of the population adversely. ${ }^{1}$ It has also caused enormous economic downfall on the already deprived and vulnerable section of the society. Among the mental health issues, stress-related problems, depression, anxiety, fear of uncertainty, and fear of future related to COVID-19 are most commonly seen. ${ }^{2,3}$ The pandemic has changed our lifestyle and has forced us to stay isolated, maintain social distance, not allowing travel, to work from home, and undergo online classes, all these producing chaos in an individual; thus, accepting the new normal might not be easy for everyone. ${ }^{4}$

People in various countries are trying to break through the restrictions, protesting against strict government policies, want freedom from these chocking situations. However, as the virus is still there with the same virulence, so there is a high risk during this period of having another wave of infection which many European countries are experiencing now. Thus, mental health issues are important as people have not adapted to major lifestyle changes along with a constant fear of contracting the virus either themselves or their close ones. ${ }^{5}$

However, the World Health Organization took several initiatives to take care of our mental health and help others who might need extra support during this difficult and testing times. ${ }^{2}$ The key points from the recommendations are having a structural routine of dayto-day activities, eat a balanced diet, exercise regularly and keep oneself fit, divide the time for work and time to relax, and enjoy with family. It is also recommended to minimize watching, reading, and listening to news related to COVID-19. However, information can be obtained from an authentic source from time to time. Social contact is important and can be done through the online platform, and people can be connected with their loved ones. Apart from all of these, they should also refrain from substance use, post positive and hopeful messages in social media, try to help others especially the elderly and other vulnerable populations, and support health care workers. Finally, not to discriminate or stigmatize anyone who had suffered from COVID-19 or the frontline healthcare workers who are risking their lives and dealing with this deadly disease. ${ }^{6-8}$

The COVID-19 pandemic has placed a tremendous strain on the mental health of frontline healthcare workers. Not only are they working long hours under extremely stressful circumstances, but
${ }^{1}$ Vice-Chancellor, Sri Balaji Vidyapeeth (Deemed to be University), Puducherry, India

${ }^{2}$ Department of Psychiatry, Mahatma Gandhi Medical College and Research Institute, Puducherry, India

Corresponding Author: Sukanto Sarkar, Department of Psychiatry, Mahatma Gandhi Medical College and Research Institute, Puducherry, India, Phone: +91 9655489210, e-mail: sukantosarkar@mgmcri.ac.in

How to cite this article: Parija SC, Sarkar S. Mental Health Challenges and COVID-19 Pandemic. J Basic Clin Appl Health Sci 2020;3(4): 135-136.

Source of support: Nil

Conflict of interest: None

many of their patients are dying despite heroic efforts to save them. In addition, many live in fear that they might contract and transmit the disease to their family and friends. ${ }^{9}$ Thus, there is also an urgent need to provide adequate psychological crisis intervention in this group to make them more productive and efficacious for optimal healthcare delivery. ${ }^{10}$

This novel disease has come up with novel challenges and requires out-of-the-box thinking and practical solution. Research and exploration into this matter have provided us with better information and have equipped us with better clinical understanding. At this testing time, the spirit of humanity has to stand tall, and with a balanced mental health armoured with positive coping skills, together we will win over this challenging situation.

\section{References}

1. Kar SK, Arafat YSM, Kabir R, Sharma P, Saxena SK. Coping with mental health challenges during COVID-19. Coronavirus Disease 2019 (COVID19) 2020. 199-213. DOI: 10.1007/978-981-15-4814-7_16.

2. World Health Organization (WHO) 2020. Mental health and COVID19. (Accessed from: http://www.euro.who.int/en/health-topics/ health-emergencies/coronavirus-covid-19/novel-coronavirus-2019ncov-technical-guidance/coronavirus-disease-covid-19-outbreaktechnical-guidance-europe/mental-healthand-covid-19. Cited 30 Jun 2020).

3. Goyal K, Chauhan P, Chhikara K, Gupta P, Singh MP. Fear of COVID 2019: first suicidal case in India. Asian J Psychiatr 2020;49:e101989. DOI: 10.1016/j.ajp.2020.101989.

4. Pfefferbaum B, North CS. Mental health and the Covid-19 pandemic. N Engl J Med 2020;383(6):510-512. DOI: 10.1056/NEJMp2008017. 
5. Coronavirus: Thousands protest in Germany against restrictions. Accessed from: https://www.bbc.com/news/world-europe-53622797 on 29th Sept 2020.

6. Rajkumar RP. COVID-19 and mental health: a review of the existing literature. Asian J Psychiatr 2020;10(52):102066. DOI: 10.1016/j. ajp.2020.102066.

7. World Health Organization (WHO). Mental Health and Psychosocial Considerations During COVID-19 Outbreak. Geneva: WHO; 2020. (Accessed from: https://www.who.int/docs/defaultsource/coronaviruse/mental-healthconsiderations.pdf? sfvrsn= 6d3578af_2).
8. Mukhta S. Mental health and psychosocial aspects of coronavirus outbreak in Pakistan: psychological intervention for public mental health crisis. Asian J Psychiatr 2020;51:102069. DOI: 10.1016/j. ajp.2020.102069.

9. Lai J, Ma S, Wang Y, Cai Z, Hu J, Wei N, et al. Factors associated with mental health outcomes among health care workers exposed to coronavirus disease 2019. JAMA Netw Open 2020;3(3):e203976. DOI: 10.1001/jamanetworkopen.2020.3976.

10. Tomlin J, Dalgleish-Warburton B, Lamph G. Psychosocial support for healthcare workers during the COVID-19 pandemic. Front Psychol 2020;11:226-232. DOI: 10.3389/fpsyg.2020.01960. 